\title{
Burnout and anxiety level of healthcare professionals during the COVID-19 pandemic in Turkey
}

\author{
Esra Dogru-Huzmeli ${ }^{a, *}$, Yagmur Cam ${ }^{\mathrm{a}}$, Senem Urfali ${ }^{\mathrm{b}}$, Ozden Gokcek $^{\mathrm{a}}$, Sabiha Bezgin ${ }^{\mathrm{a}}$, \\ Boran Urfali ${ }^{\mathrm{c}}$ and Hakan Uysal ${ }^{\mathrm{d}}$ \\ ${ }^{a}$ Department of Physiotherapy and Rehabilitaton, Health Science Faculty, Hatay Mustafa Kemal University, \\ Hatay, Turkey \\ ${ }^{\mathrm{b}}$ Department of Anesthesia and Reanimation, Tayfur Ata Sokmen Medicine Faculty, Hatay Mustafa Kemal \\ University, Hatay, Turkey \\ ${ }^{\mathrm{c} D e p a r t m e n t ~ o f ~ N e u r o s u r g e r y, ~ T a y f u r ~ A t a ~ S o k m e n ~ M e d i c i n e ~ F a c u l t y, ~ H a t a y ~ M u s t a f a ~ K e m a l ~ U n i v e r s i t y, ~ H a t a y, ~}$ \\ Turkey \\ ${ }^{\mathrm{d}}$ Vocational School of Health Services, Eskisehir Osmangazi University, Eskisehir, Turkey
}

Received 11 January 2021

Accepted 9 June 2021

\begin{abstract}
.
BACKGROUND: COVID-19 has affected many countries in the world and has been known as one of the fast-spreading viruses in recent history.

OBJECTIVE: Our aim is to reveal the level of anxiety and burnout, attitudes, thoughts, and behaviors of healthcare professionals about COVID-19 in Turkey.

METHODS: The individuals included in the study answered seven questions containing demographic information, 27 questions determining their views and perspectives on COVID-19. Anxiety level was measured by Beck Anxiety Scale (BAI), and State Anxiety Inventory (SAI); burnout was measured by Maslach Burnout Inventory (MBI).

RESULTS: We included 66 health staff (50 female, 16 male) whose mean age was 31.71 \pm 5.18 years (22-46 ranged). Twenty-two (33.3\%) of the participants worked on the COVID-19 frontline while $44(66.6 \%)$ of them worked on usual wards.

We found that participants' anxiety was at a moderate level in BAI (mean: $14.00 \pm 12.66$ ). The mean of the SAI was $49.93 \pm 13.06$. MBI subscales were low. We found that there was a significant difference in BAI between COVID-19 frontline healthcare professionals and those who worked on the usual wards $(p=0.01)$.

CONCLUSIONS: It is important to consider the level of anxiety and burnout in all healthcare professionals and to help them to protect their mental health.
\end{abstract}

Keywords: Pandemic, health staff, mental health

*Address for correspondence: Esra Dogru Huzmeli, Hatay Mustafa Kemal University, Health Science Faculty, Physiotherapy and Rehabilitation Department, Tayfur Sokmen Campus, Antakya,
Hatay, Turkey. E-mail: esradogru001@hotmail.com; Orcid ID: 0000-0002-7025-8192. 


\section{Introduction}

COVID-19 has affected many countries in the world and has been known as one of the fastspreading viruses in recent history. Various precautions have been taken in many countries to prevent transmission of the virus. Healthcare professionals are undoubtedly responsible for most of the workload in the pandemic process $[1,2]$.

Due to the large number of cases suddenly infected by COVID-19, the hospitals remained insufficient, and the patients could not receive health care under suitable conditions. Many healthcare professionals were infected, and some of them died. It is thought that health staff's workloads have been increased due to COVID-19, some of them did not go to homes to prevent contamination and all these have caused exhausted feelings and anxiety in healthcare professionals [3-5].

In this process, healthcare professionals were exposed to situations such as long working hours, insufficient medical equipment, and working with protective equipment to prevent contamination all over the world. So, their anxiety increased and they felt exhausted [6].

It has been demonstrated that anxiety developed in healthcare professionals while in the fight against such epidemic diseases. In the period of the SARS epidemic, it was shown that nurses working in the emergency room developed widespread anxiety due to long periods of working with infected patients in closed environments [7-9].

The well-being of the health personnel during the pandemic is important for the success of the treatment of patients with COVID-19 [10]. Wu et al. conducted a study to compare the severity of burnout levels between physicians and nurses on the frontline and those working on usual wards. They found that the burnout level of healthcare professionals working in the service of uninfected patients was found to be higher than that of healthcare professionals working with patients diagnosed with COVID-19. It is important to consider all the health care professionals during the COVID-19 pandemic [11].

There have been 4.323 .596 infected cases, 36.267 deaths, and 3.736.537 recoveries by 20 April 2021 in Turkey $[12,13]$. Officials took every precaution to struggle with COVID-19 in Turkey in the early days of the pandemic while no cases yet in Turkey were confirmed. Authorities established awareness of the community through the media and they prepared health systems such as medication, and respiratory system devices required for intensive care unit. We saw that the current rate of death cases in Turkey was low compared to the world. This was since our healthcare system continued to function optimally.

Few studies examined anxiety levels and attitudes of the healthcare professionals during the COVID-19 pandemic in Turkey and local studies are not enough. We conducted this study in Hatay, the south of Turkey at the borderline of Syria. Healthcare professionals are trying to provide healthcare services to both Turkish and Syrian patients in Hatay. Our aim is to reveal the level of anxiety and burnout, attitudes, thoughts, and behaviors of healthcare professionals about COVID-19 in Hatay, Turkey. Also, we want to find out whether the burnout and anxiety level of frontline COVID-19 healthcare professionals was higher than that of those who worked on the usual wards.

\section{Methods}

The study included 66 healthcare professionals who were COVID- 19 frontline healthcare professionals and who worked on usual wards. Ethics committee approval was obtained from Hatay Mustafa Kemal University Ethical Council.

\subsection{Questioning demographic characteristics and thoughts about COVID-19}

The individuals included in the study answered seven questions containing demographic information, 27 questions determining their views and perspectives on COVID-19. Anxiety level was measured by Beck Anxiety Inventory, and State Anxiety Inventory; burnout was measured by Maslach Burnout Inventory. The questionnaire was made via a link that was sent to the participants' phones on the internet (by the WhatsApp application).

A questionnaire with 27 questions was designed that included the individual's thoughts on COVID-19, changes of the individuals' lifestyle after COVID-19, COVID-19's reflections on business life, social life, and human relations, cautions, resources were used to inform about COVID-19. This questionnaire was designed by the authors. A 5-point Likert-type scale was used.

\subsection{Outcome measures}

Beck Anxiety Inventory (BAI) is a 4-point Likerttype scale with 21 items and scored between $0-3$ (0: none, 1: mild, 2: moderate, 3 : serious). BAI evaluates 
how often the individual experienced the symptoms of anxiety in the last week. A higher score indicates a higher anxiety level. The total score is calculated by finding the sum of the 21 items [14]. The validity and reliability in Turkish of BAI were determined by Ulusoy et al. [15].

The Maslach Burnout Inventory (MBI) is a 5point Likert-type scale was developed by Maslach et al. and it is scored between $0-4(0=$ Never, $1=$ Very rare, $2=$ Sometimes, $3=$ Often, $4=$ Always). MBI consists of 22 items and 3 subscales as Emotional Exhaustion (EE) (9 items), Depersonalization (DP) (5 items), and Personal Accomplishment (PA) (8 items). Scores are obtained ranging between $0-36$ for EE, 0-20 for DP, and 0-32 for PA.

In the EE and DP subscales, higher scores indicate a higher burnout while lower scores indicate an increase in burnout in PA due to the reverse scoring [16]. The validity and reliability of the MBI in Turkish were determined by Ergin et al. [17].

The State Anxiety Subscale of the State-Trait Anxiety Inventory consists of 20 questions in the 4-point Likert type ( $1=$ none, $2=$ some, $3=$ many, $4=$ completely). The State Anxiety Inventory (SAI) allows the individual to describe how he/she feels at a given moment and under certain conditions. The questions in the content of the SAI require taking into account the feelings of the individual about his/her situation while answering. The highest score obtained from SAI is 80 , while the lowest score is 20 . A higher anxiety score indicates a greater level of anxiety. Ercan et al. found that a cut-off value of 41 was optimal for SAI. The Turkish validity, reliability, and cultural adaptation of SAI were performed by Oner and LeCompte $[18,19]$.

\subsection{Statistical analysis}

Numbers and percentages were used to present descriptive characteristics of the participants. For parametric scales' correlation Pearson Correlation test was used, and for non-parametric scales' correlation Spearman Correlation test was applied. The Mann-Whitney U test was used for group comparison. The level of significance was $5 \%, r=0.40-0.75$ was accepted as moderate correlation while $0.75>r$ accepted as high correlation.

\section{Results}

We included 66 health staff (50 female, 16 male) whose mean age was $31.71 \pm 5.18$ years $(22-46$
Table 1

Characteristics of the participants

\begin{tabular}{|c|c|c|c|}
\hline & & $n$ & $\%$ \\
\hline \multirow[t]{2}{*}{ Gender } & Female & 50 & 75.8 \\
\hline & Male & 16 & 24.2 \\
\hline \multirow[t]{3}{*}{ Marital status } & Married & 32 & 48.5 \\
\hline & Single & 32 & 48.5 \\
\hline & Divorced & 2 & 3.0 \\
\hline \multirow[t]{10}{*}{ Profession } & Physician & 19 & 28.8 \\
\hline & Physiotherapist & 12 & 18.2 \\
\hline & Nurse & 22 & 33.3 \\
\hline & Health technician & 1 & 1.5 \\
\hline & Anesthesiologist & 3 & 4.5 \\
\hline & $\begin{array}{l}\text { Emergency medicine } \\
\text { technician }\end{array}$ & 1 & 1.5 \\
\hline & Nutritionist & 1 & 1.5 \\
\hline & Health officer & 1 & 1.5 \\
\hline & Dentist & 4 & 6.1 \\
\hline & Midwife & 2 & 3.0 \\
\hline \multirow[t]{7}{*}{ Education level } & Bachelor & 32 & 48.5 \\
\hline & Master of science & 12 & 18.2 \\
\hline & $\mathrm{PhD}$ & 3 & 4.5 \\
\hline & Specialist & 5 & 7.6 \\
\hline & Assistant & 8 & 12.1 \\
\hline & Associate degree & 5 & 7.6 \\
\hline & High school & 1 & 1.5 \\
\hline \multirow[t]{5}{*}{ Number of the children } & 0 & 37 & 56.1 \\
\hline & 1 & 9 & 13.6 \\
\hline & 2 & 17 & 25.8 \\
\hline & 3 & 2 & 3.0 \\
\hline & 4 & 1 & 1.5 \\
\hline \multirow{2}{*}{$\begin{array}{c}\text { Do you currently work with } \\
\text { people with COVID-19? }\end{array}$} & Yes & 22 & 33.3 \\
\hline & No & 44 & 66.7 \\
\hline \multirow{9}{*}{$\begin{array}{l}\text { When do you think that the } \\
\text { pandemic will end? }\end{array}$} & No idea & 2 & 3.0 \\
\hline & January & 2 & 3.0 \\
\hline & November & 1 & 1.5 \\
\hline & April & 1 & 1.5 \\
\hline & May & 9 & 13.6 \\
\hline & June & 22 & 33.3 \\
\hline & July & 15 & 22.7 \\
\hline & August & 7 & 10.6 \\
\hline & September & 7 & 10.6 \\
\hline
\end{tabular}

ranged). Twenty-two (33.3\%) of the participants worked on the frontline while $44(66.6 \%)$ of them worked on the usual wards (Table 1).

We found that most of the participants were afraid of the transmission of the COVID-19 (47\% strongly agree, $40.9 \%$ agree). Half of the participants were afraid that their hygiene concerns would turn into an obsession (28.8\% strongly agree, $21.2 \%$ agree). Most of the participants reported that (31.8\% strongly agree $+18.2 \%$ agree) people try to avoid them because they are healthcare professionals. $56.1 \%+24.2 \%$ (strongly agree + agree) were afraid of going home since they may cause their family to be infected (Table 2).

We found that participants' anxiety was at a moderate level in BAI (mean: $14.00 \pm 12.66$ ). The mean 
Table 2

Thoughts and feelings of the participants about COVID-19

\begin{tabular}{|c|c|c|c|c|c|c|c|c|c|c|}
\hline \multirow[b]{2}{*}{ I' $m$ afraid of the transmission of COVID-19 } & \multicolumn{2}{|c|}{$\begin{array}{l}\text { Strongly } \\
\text { agree }\end{array}$} & \multicolumn{2}{|c|}{ Agree } & \multicolumn{2}{|c|}{$\begin{array}{l}\text { Agree a } \\
\text { little }\end{array}$} & \multicolumn{2}{|c|}{$\begin{array}{l}\text { Do not } \\
\text { agree }\end{array}$} & \multicolumn{2}{|c|}{$\begin{array}{c}\text { Strongly } \\
\text { do not } \\
\text { agree }\end{array}$} \\
\hline & 31 & 47.0 & 27 & 40.9 & 5 & 7.6 & 3 & 4.5 & 0 & 0 \\
\hline I feel pessimistic and hopeless & 22 & 33.3 & 18 & 27.3 & 16 & 24.2 & 8 & 12.1 & 2 & 3.0 \\
\hline I'm worried while working with patients that have fever & 29 & 43.9 & 22 & 33.3 & 9 & 13.6 & 1 & 1.5 & 5 & 7.6 \\
\hline I'm angry with the infected patients & 3 & 4.5 & 6 & 9.1 & 16 & 24.2 & 19 & 28.8 & 22 & 33.3 \\
\hline I follow the disinfection procedures & 27 & 40.9 & 27 & 40.9 & 9 & 13.6 & 2 & 3.0 & 1 & 1.5 \\
\hline COVID-19 will end when the weather gets warmer & 7 & 10.6 & 11 & 16.7 & 21 & 31.8 & 15 & 22.7 & 12 & 18.2 \\
\hline $\begin{array}{l}\text { I'm afraid that my hygiene concerns will turn into } \\
\text { obsession }\end{array}$ & 19 & 28.8 & 14 & 21.2 & 11 & 16.7 & 12 & 18.2 & 10 & 15.2 \\
\hline I have an important role in protecting public health & 29 & 43.9 & 23 & 34.8 & 9 & 13.6 & 3 & 4.5 & 2 & 3.0 \\
\hline $\begin{array}{l}\text { People try to avoid me because I am a healthcare } \\
\text { professional }\end{array}$ & 21 & 31.8 & 12 & 18.2 & 15 & 22.7 & 14 & 21.2 & 4 & 6.1 \\
\hline $\begin{array}{l}\text { I am afraid of going home from causing my family to be } \\
\text { infected }\end{array}$ & 37 & 56.1 & 16 & 24.2 & 7 & 10.6 & 2 & 3.0 & 4 & 6.1 \\
\hline I am undecided while working & 9 & 13.6 & 15 & 22.7 & 18 & 27.3 & 17 & 25.8 & 7 & 10.6 \\
\hline I am thinking of resigning & 4 & 6.1 & 1 & 1.5 & 6 & 9.1 & 20 & 30.3 & 35 & 53.0 \\
\hline I do not want to work any more & 12 & 18.2 & 11 & 16.7 & 12 & 18.2 & 23 & 34.8 & 8 & 12.1 \\
\hline $\begin{array}{l}\text { My workload has increased too much since the } \\
\text { COVID-19 pandemic }\end{array}$ & 9 & 13.6 & 9 & 13.6 & 16 & 24.2 & 16 & 24.2 & 16 & 24.2 \\
\hline $\begin{array}{l}\text { My performance at work has decreased since the } \\
\text { COVID-19 pandemic }\end{array}$ & 12 & 18.2 & 15 & 22.7 & 18 & 27.3 & 16 & 24.2 & 5 & 7.6 \\
\hline $\begin{array}{l}\text { My concentration has decreased since the COVID-19 } \\
\text { pandemic }\end{array}$ & 16 & 24.2 & 12 & 18.2 & 25 & 37.9 & 9 & 13.6 & 4 & 6.1 \\
\hline I feel irritated & 19 & 28.8 & 16 & 24.2 & 15 & 22.7 & 13 & 19.7 & 3 & 4.5 \\
\hline I have insomnia due to the COVID-19 pandemic & 9 & 13.6 & 5 & 7.6 & 19 & 28.8 & 20 & 30.3 & 13 & 19.7 \\
\hline $\begin{array}{l}\text { I am insensitive and unresponsive to events due to the } \\
\text { COVID-19 pandemic }\end{array}$ & 7 & 10.6 & 13 & 19.7 & 16 & 24.2 & 19 & 28.8 & 11 & 16.7 \\
\hline $\begin{array}{l}\text { I feel as if everything is infected due to the COVID-19 } \\
\text { pandemic }\end{array}$ & 18 & 27.3 & 16 & 24.2 & 14 & 21.2 & 13 & 19.7 & 5 & 7.6 \\
\hline I always feel dirty since the COVID-19 pandemic & 20 & 30.3 & 20 & 30.3 & 10 & 15.2 & 13 & 19.7 & 3 & 4.5 \\
\hline I'm surprised by the events & 16 & 24.2 & 28 & 42.4 & 10 & 15.2 & 10 & 15.2 & 2 & 3.0 \\
\hline $\begin{array}{l}\text { My awareness of events and people decreased after the } \\
\text { COVID-19 pandemic }\end{array}$ & 7 & 10.6 & 5 & 7.6 & 16 & 24.2 & 21 & 31.8 & 17 & 25.8 \\
\hline $\begin{array}{l}\text { I am trying to escape from the news and information } \\
\text { about the COVID-19 pandemic }\end{array}$ & 3 & 4.5 & 4 & 6.1 & 5 & 7.6 & 24 & 36.4 & 30 & 45.5 \\
\hline I want to stay away from other people & 23 & 34.8 & 24 & 36.4 & 10 & 15.2 & 7 & 10.6 & 2 & 3.0 \\
\hline $\begin{array}{l}\text { I always watch the news in my spare time since the } \\
\text { COVID-19 pandemic }\end{array}$ & 17 & 25.8 & 23 & 34.8 & 15 & 22.7 & 9 & 13.6 & 2 & 3.0 \\
\hline $\begin{array}{l}\text { I am using social media more than I did before the } \\
\text { COVID-19 pandemic }\end{array}$ & 19 & 28.8 & 16 & 24.2 & 17 & 25.8 & 10 & 15.2 & 4 & 6.1 \\
\hline
\end{tabular}

of the SAI was $49.93 \pm 13.06$. MBI subscales were low (Table 3).

We found that there was a significant difference in BAI between frontline COVID-19 healthcare professionals and those who worked on the usual wards $(p=0.01)$, (Table 4, Fig. 1).

There was a positive, significant, and moderate correlation between BAI, and SAI $(r=0.537)$; between BAI, and MBI-EE Subscale $(r=0.405)$. There was a positive, significant, and moderate correlation between SAI, and MBI-EE Subscale $(r=0.540)$; between SAI, and MBI-DP Subscale $(r=0.481)$. There was a positive, significant, and moderate correlation between MBI-EE Subscale, and MBI-DP Subscale $(r=0.543)$, (Table 5).

\section{Discussion}

As a result of our study, it has been shown that healthcare professionals working with patients diagnosed with COVID-19 had low-moderate levels of anxiety and their anxiety status was associated with emotional exhaustion and depersonalization. As a result, it has been shown that healthcare professionals were afraid of COVID-19 transmission, so they felt 
Table 3

Beck Anxiety Inventory, State Anxiety Inventory, and Maslach Burnout Inventory Scales' scores

\begin{tabular}{|c|c|c|c|}
\hline & & Mean \pm SD & Min-Max \\
\hline Beck Anxiety Inventory & & $14.00 \pm 12.66$ & $0-55$ \\
\hline State Anxiety Inventory & & $49.93 \pm 13.06$ & $21-80$ \\
\hline \multirow[t]{3}{*}{ Maslach Burnout Inventory Emotional Exhaustion } & Emotional Exhaustion Subscale & $15.74 \pm 7.72$ & $0-34$ \\
\hline & Depersonalization Subscale & $5.37 \pm 4.07$ & $0-17$ \\
\hline & Personal Accomplishment Subscale & $19.09 \pm 5.50$ & $5-31$ \\
\hline
\end{tabular}

Table 4

Differences between frontline COVID-19 healthcare professionals and those who worked on the usual wards

\begin{tabular}{|c|c|c|c|c|c|c|}
\hline & \multicolumn{2}{|c|}{$\begin{array}{l}\text { COVID-19 } \\
\text { frontline } \\
\text { healthcare } \\
\text { professionals } \\
n=22\end{array}$} & \multicolumn{2}{|c|}{$\begin{array}{c}\text { Usual } \\
\text { ward } \\
\text { healthcare } \\
\text { professionals } \\
n=44\end{array}$} & \multirow[b]{2}{*}{$\mathrm{z}$} & \multirow[b]{2}{*}{$p$} \\
\hline & $\mathrm{X}$ & SD & $\mathrm{X}$ & $\mathrm{SD}$ & & \\
\hline Beck Anxiety Inventory & 20.95 & 15.80 & 10.61 & 9.52 & -2.56 & 0.01 \\
\hline State Anxiety Inventory & 50.90 & 14.36 & 49.27 & 12.61 & -0.59 & 0.55 \\
\hline MBI Emotional Exhaustion & 17.71 & 8.33 & 14.79 & 7.42 & -0.98 & 0.32 \\
\hline MBI Depersonalization & 5.80 & 5.13 & 5.18 & 3.55 & -0.81 & 0.41 \\
\hline MBI Personal Accomplishment & 19.66 & 6.11 & 18.75 & 5.28 & -0.09 & 0.92 \\
\hline
\end{tabular}

Mann-Whitney U test, MBI: Maslach Burnout Inventory.

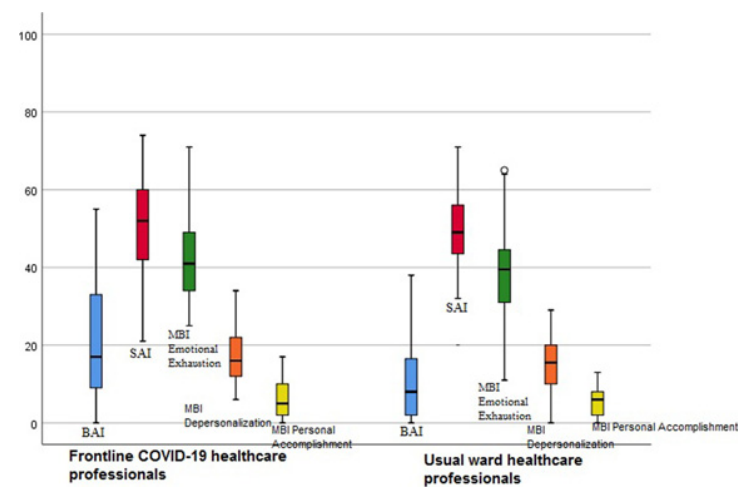

Fig. 1. Burnout and anxiety level of frontline COVID-19 healthcare professionals and those who worked on the usual wards.

pessimistic and unhappy, and nervous while working with patients with fever. They reported that they felt irritated, they regarded everything and themselves as dirty, they were afraid to go home and infect their families, and were afraid that their habit of hygiene in this process will turn into an obsession. We found that frontline COVID-19 healthcare professionals had higher anxiety levels than those who worked on the usual wards.

Most of them reported that (31.8\% strongly agree + $18.2 \%$ agree) people tried to avoid them because they are healthcare professionals. They stated that especially this situation made them extremely unhappy since the healthcare professionals that were liv- ing alone were completely isolated. They reported that both their families and friends wanted to avoid them.

Most of the healthcare professionals were afraid (56.1\% strongly agree $+24.2 \%$ agree) of infecting their families. So, some of them reported that they did not want to go home.

The World Health Organization defines burnout not as a health problem, but as a chronic workplace stress situation [20]. It is a psychological condition such as energy depletion, negative emotions about work. It is widely seen among healthcare professionals. MBI is widely used in the assessment of burnout. MBI Emotional exhaustion is the feeling of being exhausted and overloaded by the person's profession; depersonalization means the individual does not feel emotional about the people she/he serves. The personal accomplishment section defines the person's feelings of successfully overcoming the problems $[16,17]$.

MBI scores are obtained ranging between 0-36 for EE, 0-20 for DP, and 0-32 for PA [16, 17]. We found that $\mathrm{EE}$ mean was $15.74 \pm 7.72$; the mean of the EE was at an average burnout level. DP mean was $5.37 \pm 4.07$ and participants were at a low level of burnout. PA mean was $19.09 \pm 5.50$, and this mean was at a low level. But the MBI-EE, MBI-DP, MBIPA scores were higher in healthcare professionals that working with COVID-19 patients more than not working with COVID-19 patients. The difference was 
Table 5

Correlation between age, Beck Anxiety Inventory, State Anxiety Inventory, and Maslach Burnout Inventory Scales

\begin{tabular}{|c|c|c|c|c|c|c|c|}
\hline & & Age & $\begin{array}{c}\text { Beck } \\
\text { Anxiety } \\
\text { Inventory }\end{array}$ & $\begin{array}{c}\text { State } \\
\text { Anxiety } \\
\text { Scale }\end{array}$ & $\begin{array}{c}\text { MBI } \\
\text { Emotional } \\
\text { Exhaustion }\end{array}$ & $\begin{array}{c}\text { MBI } \\
\text { Depersonalization }\end{array}$ & $\begin{array}{c}\text { MBI } \\
\text { Personal } \\
\text { Accomplishment }\end{array}$ \\
\hline Age & $\mathbf{r}$ & 1 & & & & & \\
\hline Beck Anxiety Inventory & $\begin{array}{l}\mathbf{p} \\
\mathbf{r} \\
\mathbf{p}\end{array}$ & $\begin{array}{c}-0.044^{*} \\
0.724\end{array}$ & $\begin{array}{l}1 \\
-\end{array}$ & & & & \\
\hline State Anxiety Scale & $\begin{array}{l}\text { r } \\
\text { p }\end{array}$ & $\begin{array}{c}0.012^{*} \\
0.921\end{array}$ & $\begin{array}{c}\mathbf{0 . 5 3 7}^{* *} \\
0.000\end{array}$ & $\begin{array}{l}1 \\
-\end{array}$ & & & \\
\hline MBI Emotional exhaustion & r & $\begin{array}{c}-0.111^{*} \\
0.374\end{array}$ & $\begin{array}{c}0.351^{* *} \\
0.004\end{array}$ & $\begin{array}{c}\mathbf{0 . 5 4 0}^{*} \\
0.000\end{array}$ & $\begin{array}{l}1 \\
-\end{array}$ & & \\
\hline MBI Depersonalization & $\begin{array}{l}\mathbf{r} \\
\mathbf{p}\end{array}$ & $\begin{array}{c}-0.099^{*} \\
0.429\end{array}$ & $\begin{array}{c}0.202^{* *} \\
0.104\end{array}$ & $\begin{array}{c}\mathbf{0 . 4 8 1}^{*} \\
0.000\end{array}$ & $\begin{array}{c}\mathbf{0 . 5 4 3}^{*} \\
0.000\end{array}$ & 1 & \\
\hline MBI Personal accomplishment & $\begin{array}{l}\mathbf{r} \\
\mathbf{p}\end{array}$ & $\begin{array}{c}-0.054^{*} \\
0.669\end{array}$ & $\begin{array}{c}-0.001^{* *} \\
0.993\end{array}$ & $\begin{array}{c}-0.225^{*} \\
0.069\end{array}$ & $\begin{array}{c}-0.020^{*} \\
0.871\end{array}$ & $\begin{array}{c}-0.016^{* *} \\
0.897\end{array}$ & $\begin{array}{l}1 \\
-\end{array}$ \\
\hline
\end{tabular}

*Pearson Correlation, ${ }^{* *}$ Spearman Correlation, MBI: Maslach Burnout Inventory.

not significant but if even one of the healthcare professionals had burnout, we should consider it and try to help her/him. We concluded that there was a moderate correlation between SAI and MBI-EE; BAI and MBI-EE. Emotional exhaustion was correlated with anxiety.

Emotional burnout can occur even if the workload of the person is not very high. As a matter of fact, it was revealed that the workload of the individuals participating in our study did not increase much after the pandemic. Transmission anxiety caused more burnout levels than the workload. We did not find a significant difference between those working on the frontline and those working on the usual wards.

Individuals experiencing burnout during the pandemic should seek professional help. Some micropractices were advised by Fessel et al., who reported that any small touch that will make one feel good will reduce the sense of burnout. This small touch will not treat burnout, but it may prevent it. Practices that decrease anxiety will provide less burnout [21].

Psychological support is given to the healthcare professionals in Turkey by psychological departments. Authorities are trying to generalize this to all hospitals and all individuals. Even though there is such an opportunity, healthcare professionals may not realize that they need psychological support. For this reason, authorities may warn the department chiefs of the hospitals to check their staff's well-being regularly and to encourage them to go to the psychologist.

In a study conducted in China, it has been reported that healthcare professionals who take a role in the fight against COVID-19 are at risk of anxiety, and depression depending on many factors [22]. Long-term working with protective clothing and mask equipment, disconnection with their families, anxiety about disease transmission, and transportation have been reported as factors that increase their existing anxiety [23, 24]. As a result of our study, quite similar results have been revealed.

The individuals in our study stated that their relatives and friends stay away from them because they are healthcare professionals. Being a healthcare professional caused stigma in the pandemic period. They stated that even their partners were afraid to meet them. Besides, it has been revealed that they constantly wash their hands against the risk of infection and that they are afraid that this will turn into an obsession. Fear of transmitting the infection to the family caused some healthcare professionals to leave their homes and stay in places like guest homes, hotels. This increased people's anxiety and burnout. It was found that the individuals participating in the study had low burnout in all burnout subscales.

The negative effect of the feeling of being infected fear on individuals is known [25]. As a result of the studies on the mental health of health workers struggling with COVID 19, the negative impact of this situation was emphasized [26-29]. In our study, we found that participants feel uneasy and afraid of getting infected while working with patients with fever. "Keeping all staff protected from chronic stress and poor mental health during the pandemic response means that they will have a better capacity to fulfill their roles." [30].

Participants had a moderate level of anxiety with BAI. But when we analyzed the anxiety and burnout difference between COVID-19 frontline healthcare professionals and those not working with COVID-19, we found that COVID-19 frontline healthcare pro- 
fessionals had a higher anxiety level than those who worked on the usual wards $(p=0.01)$.

SAI evaluates the current state of anxiety, asking how respondents feel "right now". Some authors defined a cut point of 39-40. Ercan et al. reported that 41 cut-off is optimal for SAI [19, 30-32]. Knight et al. conducted a study in which they included 110 participants and they found a mean score of the SAI was 29.92 for males, 34.47 for females [31]. We found that the mean SAI score was $49.93 \pm 13.06$. This means health care workers suffer from moderate level anxiety in SAI.

The BAI is a brief measure of anxiety with a focus on somatic symptoms of anxiety. BAI questions physical symptoms related to anxiety such as tremors, weakness, and hot flushes in the legs. The following guidelines are recommended for the interpretation of scores: $0-9$, normal or no anxiety; 10-18, mild to moderate anxiety; 19-29, moderate to severe anxiety; and 30-63, severe anxiety $[14,33]$. In our study, we found the mean of the BAI was $14.00 \pm 12.66$. They have a moderate anxiety level in BAI.

People were afraid of being infected by COVID-19 thus they did not want to go to the hospital except in emergencies during the early term of the pandemic. Therefore, the workload of the healthcare professionals who worked on the usual wards had been shown not to have increased so much. Therefore, it has been observed that one of the causes of emotional burnout is the fear of being infected. It was found that COVID-19 frontline healthcare professionals had higher anxiety and burnout than those who worked on the usual wards in most of the scales in our study. However, there was no significant difference in the burnout level between them. In case we included more COVID-19 frontline healthcare professionals in our study we would find a significant difference between professionals who worked frontline and those worked on the usual wards. In Fig. 1, it is shown that COVID-19 frontline healthcare professionals' scores of almost all scales were higher.

Healthcare professionals had to work as much as they did not work throughout their careers during the pandemic process. Correspondingly, health officials stated that they would reward healthcare workers with financial support and they this financial support reward motivated them. But unfortunately their relatives' jobs were affected negatively through the pandemic. Tradesmen and private sector employees were adversely affected by the pandemic throughout the country because of the closing all the shops and workplaces. Even if healthcare professionals did not be affected financially directly, financial difficulties experienced by their relatives have been an important problem and an important factor that increased their anxiety level.

Fifty of the participants were female health workers in our study. A woman is a person who assumes primary responsibility for the house, for the family, and for child care in Turkey. When the mother is not at home, the household habits such as cooking and cleaning, and children are neglected which may have caused a high anxiety rate of the individuals in our study. Because female healthcare professionals' bodies were at the hospital but their minds were at home. In addition, the female healthcare professionals' fear of being infected in the hospital, and the risk of bringing the infection to home increased the anxiety.

Work-life balance is the key to success both at work and in social life. However, during the pandemic period, healthcare professionals had to work much above their power. Some healthcare professionals could not go home for days and had to work without rest. In addition, working with masks and visors also caused people to perceive their workload as heavier. However, resting properly affected healthcare professionals' focusing level at work, success in patients' treatment, and their patience.

The anxiety and burnout of the health personnel working in the frontlines may be at a level that will require psychologist support. Wu et al. reported that "both frontline and ordinary ward health staff should be taken into consideration when designing policies and procedures to support the welfare of healthcare professionals in the face of the COVID-19 crisis" [33-35]. In the time of the pandemic, the level of anxiety of all healthcare professionals increased [36]. Therefore, necessary measures must be taken to protect the mental well-being of all healthcare professionals.

Babamiri et al. reported that researches on reducing burnout in healthcare professionals in the COVID-19 outbreak were limited. Such researches may provide a clinical practice guideline to reduce burnout in health workers as the frontline soldiers against outbreaks such as SARS and COVID-19 [37].

One of our limitations was the small study group. We recommend future studies to include more subjects in each job group and to compare them. Also, we think that the fact that healthcare professionals working in Hatay had to provide health services to both Turkish and Syrian patients may have increased 
their anxiety during the COVID-19 period. However, we did not question this. We recommend this to be questioned in future studies.

\section{Conclusions}

There was an important level of anxiety and burnout in COVID-19 frontline healthcare professionals and in who worked on the usual ward. However COVID-19 frontline healthcare professionals had higher anxiety and burnout. Burnout feeling caused exhaustion and motivation loss while working. It was considered to be very important to provide support for health professionals in order to protect their mental health. So, authorities should plan individual psychological visits for healthcare professionals by psychologists to reduce their anxiety and burnout feelings. It should be reminded that healthcare professionals should also consider their health while working with patients with COVID-19.

\section{Conflict of interest}

There is no conflict of interest to report.

\section{References}

[1] World Health Organization. [cited 2021 Apr 20] Available from: https://www.who.int/emergencies/diseases/novelcoronavirus-2019.

[2] World Health Organization. Coronavirus disease (COVID19) outbreak: rights, roles and responsibilities of health workers, including key considerations for occupational safety and health. Interim guidance. [updated 2020 Mar 19; cited 2021 Apr 20] Available from: https://apps. who.int/iris/ bitstream/handle/10665/331510/WHO-2019-nCov-HCW advice-2020.2-eng.pdf.

[3] World Health Organization. [cited 2021 Apr 20] Available from: https://www.who.int/emergencies/diseases/novelcoronavirus-2019/technical-guidance

[4] Albott CS, Wozniak JR, McGlinch BP, Wall MH, Gold BS, Vinogradov S. Battle Buddies: Rapid Deployment of a Psychological Resilience Intervention for Health Care Workers During the COVID-19 Pandemic. Anesth Analg. 2020;131 (1):43-54. doi:10.1213/ANE.0000000000004912

[5] Liu Q, Luo D, Haase JE, Guo Q, Wang XQ, Liu S, Xia L, Liu Z, Yang J, Yang BX. The experiences of health-care providers during the COVID-19 crisis in China: a qualitative study. The Lancet Glob. Health. 2020;8(6):e790-e798.

[6] ICN. [updated 2020 Apr 29; cited 2021 Apr 20] Available from: https://www.icn.ch/news/icn-calls-governmentaction-stop-attacks-nurses-time-when-their-mental-healthand-wellbeing

[7] Wong TW, Yau JKY, Chan CLW, Kwong RSY, Ho SMY, Lau CC, Lau FL, Lit CH. The psychological impact of severe acute respiratory syndrome outbreak on healthcare workers in emergency departments and how they cope. Eur J Emerg Med. 2005;12(1):13-8.

[8] Li L, Cheng S, Gu J. SARS infection among health care workers in Beijing, China. JAMA. 2003;290(20):2662-3.

[9] Shih FJ, Gau ML, Kao CC, Yang CY, Lin YS, Liao YC, Sheu SJ. Dying and caring on the edge: Taiwan's surviving nurses' reflections on taking care of patients with severe acute respiratory syndrome. Appl Nurs Res. 2007;20(4):171-80.

[10] Chen Q, Liang M, Li Y, Gou J, Fei D, Wang L, He L, Sheng C, Cai Y, Li X, Wang J, Zang Z. Mental health care for medical staff in China during the COVID-19 outbreak. Lancet Psychiatry. 2020;7(4):e15-e16.

[11] Wu P, Fang Y, Guan Z, Fan B, Kong J, Yao Z, Liu X, Fuller CJ, Susser E, Lu J, Hoven CW. The psychological impact of the SARS epidemic on hospital employees in China: exposure, risk perception, and altruistic acceptance of risk. Can J Psychiatry. 2009;54(5):302-11.

[12] World Health Organization. [updated 2021 April, cited 2021 Apr 20] Available from: https://www.who.int/emergencies/ diseases/novel-coronavirus-2019/situation-reports

[13] Turkish Ministry of Health. Available from: https://covid19. saglik.gov.tr/

[14] Beck AT, Epstein N, Brown G, Steer RA. An inventory for measuring clinical anxiety: psychometric properties. J Consult Clin Psychol. 1988;56(6):893-7.

[15] Ulusoy M, Sahin NH, Erkmen H. The Beck anxiety inventory: psychometric properties. J Cogn Psychother. 1998; 12(2):163-72.

[16] Maslach C, Jackson SE, Leiter WB, Schaufeli RL, Schwab RL. Maslach burnout inventory. Palo Alto, CA: Consulting psychologists press. 1986;21:3463-4.

[17] Ergin C. Adaptation of burnout and Maslach burnout scale for doctors and nurses. VII. National Psychology Congress, Ankara (Turkey): 1992 Sep 22.

[18] Oner N, Le Compte A. Handbook of State-Trait Anxiety Inventory. Istanbul: Publish of Bogazici University; 1983.

[19] Ercan I, Hafizoglu S, Ozkaya G, Kirli S, Yalcintas E, Akaya C. Examining cut-off values for the state-trait anxiety inventory. Rev Argentina de Clin Psicol. 2015;24(2):143-8.

[20] World Health Organization. [updated 2019 May 28, cited 2021 Apr 20]. Available from: https://www.who.int/ mental_health/evidence/burn-out/en/

[21] Fessell D, Cherniss C. Coronavirus Disease 2019 (COVID19) and Beyond: Micropractices for Burnout Prevention and Emotional Wellness. J Am Coll Radiol. 2020;17(6): 746-8.

[22] Liu Z, Han B, Jiang R, Huang Y, Ma C, Wen J, Zhang T, Wang Y, Chen H, Ma Y. Mental health status of doctors and nurses during COVID-19 epidemic in China. 2020. Available at SSRN 3551329.

[23] Lu W, Wang H, Lin Y, Li L. Psychological status of medical workforce during the COVID-19 pandemic: A crosssectional study. Psychiatry Res. 2020;288:112936

[24] Liu CY, Yang YZ, Zhang XM, Xu X, Dou QL, Zhang WW. The prevalence and influencing factors for anxiety in medical workers fighting COVID-19 in China: A cross-sectional survey. Available at SSRN 3548781.

[25] Furer P, Walker JR, Chartier MJ, Stein MB. Hypochondriacal concerns and somatization in panic disorder. Depress Anxiety. 1997;6(2):78-85.

[26] Huang Y, Zhao N. Chinese mental health burden during the COVID-19 pandemic. Asian J Psychiatr. 2020;51:102052.

[27] Lai J, Ma S, Wang Y, Cai Z, Hu J, Wei N, Wu J, Du H, Chen T, Li R, Tan H, Kang L, Yao L, Huang M, Wang H, Wang G, Liu 
Z, Hu S. Factors Associated With Mental Health Outcomes Among Health Care Workers Exposed to Coronavirus Disease 2019. JAMA Netw Open. 2020;3(3):e203976.

[28] Su TP, Lien TC, Yang CY, Su YL, Wang JH, Tsai SL, Yin JC. Prevalence of psychiatric morbidity and psychological adaptation of the nurses in a structured SARS caring unit during outbreak: a prospective and periodic assessment study in Taiwan. J Psychiatr Res. 2007;41(1-2):119-30.

[29] Huang Y, Zhao N. Generalized anxiety disorder, depressive symptoms and sleep quality during COVID-19 outbreak in China: a web-based cross-sectional survey. Psychiatry Res. 2020;288:112954.

[30] World Health Organization. [updated 2020 May 18, cited 2021 Apr 20]. Available from: https://www.who.int/docs/ default-source/coronaviruse/mental-health-considerations. pdf

[31] Knight RG, Waal-Manning HJ, Spears GF. Some norms and reliability data for the State-Trait Anxiety Inventory and the Zung Self-Rating Depression scale. Br J Clin Psychol. 1983;22(Pt 4):245-9.

[32] Kayikcioglu O, Bilgin S, Seymenoglu G, Deveci A. State and Trait Anxiety Scores of Patients Receiving Intravitreal Injections. Biomed Hub. 2017;2(2):1-5.

[33] Julian LJ. Measures of anxiety: State-Trait Anxiety Inventory (STAI), Beck Anxiety Inventory (BAI), and
Hospital Anxiety and Depression Scale-Anxiety (HADSA). Arthritis Care Res (Hoboken). 2011;63(Suppl 11)(0 11):S467-S472.

[34] Wu Y, Wang J, Luo C, Hu S, Lin X, Anderson AE, Bruera E, Yang X, Wei S, Qian Y. A Comparison of Burnout Frequency Among Oncology Physicians and Nurses Working on the Frontline and Usual Wards During the COVID-19 Epidemic in Wuhan, China. J Pain Symptom Manage. 2020; 60(1):e60-e65.

[35] Wu H, Liu L, Sun W, Zhao X, Wang J, Wang L. Factors related to burnout among Chinese female hospital nurses: cross-sectional survey in Liaoning Province of China. J Nurs Manag. 2014;22(5):621-9.

[36] Karlsson U, Fraenkel CJ. Covid-19: risks to healthcare workers and their families. BMJ. 2020;371:m3944.

[37] Babamiri M, Alipour N, Heidarimoghadam R. Research on reducing burnout in health care workers in critical situations such as the COVID-19 outbreak. Work. 2020;66(2):379-80. 